\title{
Geranylgeraniol Reverses the Toxicity Induced by Clinical Doses of Zoledronic Acid on Gingival Epithelial Cells and Gingival Fibroblasts
}

Filip Koneski ${ }^{1,2 *}$, David Tipton ${ }^{1}$, Jegdish Babu, Danica Popovic-Monevska ${ }^{2}$, Vladimir Popovski ${ }^{2}$, Alberto Benedetti ${ }^{2}$, Suzana Dvojakovska-Bozovic², Aleksandar Iliev², Goran Panchevski², Antonio Kirkov², Aleksandar Grchev², Aleksandar Stamatoski ${ }^{2}$, Franklin Garcia-Godoy ${ }^{1}$

${ }^{1}$ Department of Bioscience Research, College of Dentistry, University of Tennessee, Memphis, Tennessee, USA; ${ }^{2}$ University Clinic for Maxillofacial Surgery in Skopje, Faculty of Dentistry, Ss. Cyril and Methodius University in Skopje, Macedonia

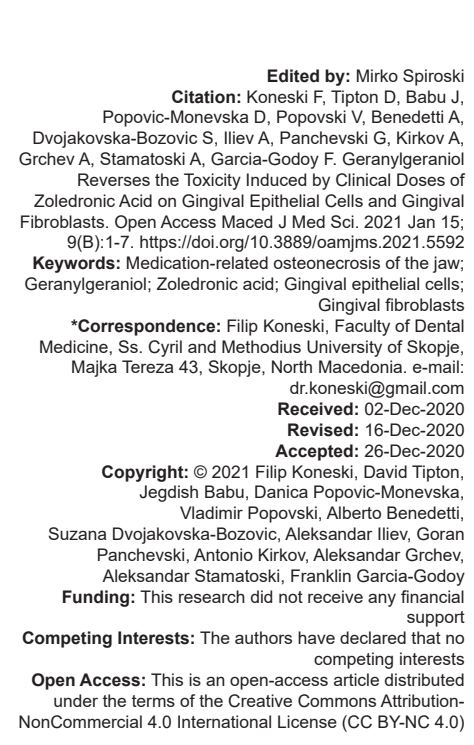

\section{Abstract}

BACKGROUND: Medication-related osteonecrosis of the jaw (MRONJ) is of considerable concern among clinicians and researchers, with no clear pathology mechanism, preventive, or treatment protocols.

AIM: This study aimed to assess the effects of geranylgeraniol (GGOH) on the toxicity induced by clinical doses of zoledronic acid (ZOL) on gingival epithelial cells and gingival fibroblasts in vitro.

METHODS: Human gingival fibroblasts and gingival epithelial cells were treated with 5,25 , or $50 \mu \mathrm{M} \mathrm{ZOL} \pm 50 \mu \mathrm{M}$ GGOH for 3 days. Viability of the cells was determined using the 3-[4, 5-dimethylthiazol-2-yl]-2,5-diphenyl tetrazolium bromide assay. Calculation of percentage of the control group, analysis of variance and Tukey post-hoc comparisons were performed to test the significance between groups, which was set at $p=0.05$. Cell morphology was evaluated using light microscopy.

RESULTS: ZOL significantly reduced the viability of both epithelial cells and fibroblasts at all concentrations $(p<0.05)$ with the exception of fibroblasts at concentration of $5 \mu \mathrm{M}(\mathrm{p}=0.44)$. GGOH had positive effects on the viability of the cells treated with ZOL at all concentrations. However, statistically significant improvement was obtained only in epithelial cells at 5 and $25 \mu \mathrm{M}$ ZOL. The cell morphology of both types of cells was improved after addition of GGOH.

CONCLUSION: GGOH reverses the toxic effects of clinical doses of ZOL on gingival epithelial cells and has slightly positive, but not significant effects on gingival fibroblasts. This study suggests that GGOH may be effective in the prevention and treatment of MRONJ.

\section{Introduction}

Medication-related osteonecrosis of the jaw (MRONJ) has become one of the most challenging issues in oral and maxillofacial surgery. This is mainly due to the increasing number of patients with the disease and the lack of effective treatment. The term MRONJ has recently replaced the previously used term "bisphosphonate-related osteonecrosis of the jaw" because of the use of new antiresorptive medications which can cause osteonecrosis [1]. However, bisphosphonates (BPs) are still one of the most widely used classes of antiresorptive drugs in patients with malignancy and its complications, hypercalcemia, bone metastasis, osteoporosis, and other metabolic bone diseases. Therefore, they remain one of the most prevalent medications associated with the occurrence of MRONJ.
The major hypothesis for the pathogenesis of MRONJ involves the toxic effects of BPs, mainly on osteoclasts, and subsequent altered bone metabolism after an invasive surgical procedure on the jaws. However, new knowledge that may explain other possible mechanisms of the disease has been gained from recent studies that examined the toxic effects of the BPs on soft-tissue cells, infection, inflammatory conditions, and decreased local $\mathrm{pH}$ [2]. The negative effects of both non-nitrogen- and nitrogen-containing BPs on cell viability, morphology, migration, and proliferation have been demonstrated on gingival epithelial cells, gingival fibroblasts, endothelial cells, periodontal ligament cells, and osteoblasts [3], [4], [5], [6], [7], [8], [9], [10], [11], [12] .

The major risk factor for MRONJ remains invasive dental procedures and the resulting wound. MRONJ has been successfully reproduced in animal models, providing data for its occurrence and 
development [13], [14]. In a recent study, osteonecrotic changes were seen even after only a soft-tissue trauma was inflicted [15]. Unlike osteoradionecrosis, where the main factor is the negative effect of radiotherapy on the jaws' vascularization [16], MRONJ occurs because of the toxic effects of BPs on the various soft and bone tissue cells.

The main point of action of the nitrogencontaining BPs is the mevalonate biosynthetic pathway, which produces lipids which function to prenylate (addition of hydrophobic molecules) and activate small GTPases, signaling molecules essential for normal cell function and survival. In particular, BPs inhibit the action of farnesyl diphosphate synthase, the production of geranylgeranyl pyrophosphate (GGPP) [17] and ultimately, protein prenylation [18], [19]. To date, the actions of geranylgeraniol (GGOH), an isoprenoid that is converted to GGPP in the mevalonate pathway, has been analyzed in only a few studies [6], [20], [21], [22], [23], [24] Moreover, there are two animal studies in which $\mathrm{GGOH}$ decreased the occurrence and development of MRONJ [25] and improved the bone deposition near extraction sites [26].

Nevertheless, the types of BPs and their concentrations were quiet diverse in the mentioned cell studies. Therefore, additional studies based on calculated BPs concentrations that correspond to the clinical concentrations used in patients are needed.

This study aims to assess the effects of GGOH on the toxicity induced on gingival epithelial cells and gingival fibroblasts in vitro, by clinical doses of zoledronic acid (ZOL) that represent 6-month, 2-year and 4-year duration of treatment in patients.

\section{Materials and Methods}

Human gingival epithelial cells and human gingival fibroblasts were used in this study. The toxicity of ZOL and the effects of GGOH were assessed through testing cell viability and cell morphology with the 3-[4, 5-dimethylthiazol-2-yl]-2,5-diphenyl tetrazolium bromide (MTT) test and microscopic evaluation, respectively.

\section{Cell lines}

A human gingival fibroblast cell line (designated GN23) was acquired from the Craniofacial Research Center at the University of Tennessee College of Dentistry, Department of Bioscience Research in Memphis, Tennessee, USA. It was previously derived from non-inflamed gingival tissue obtained from a healthy patient, as described in our previous study [27]. The Smulow-Glickman (S-G) human gingival epithelial cell line used in this study was originally derived from clinically normal attached gingival [28], [29] and was obtained from Kasten et al., East Tennessee State University, Quillen College of Medicine, Johnson City, Tennessee, USA [30]. The cells were cultured in Dulbecco's Modified Eagle Medium (DMEM; Life Technologies; Grand Island, NY) supplemented with $100 \mu \mathrm{g} / \mathrm{ml}$ gentamicin (Sigma-Aldrich; St. Louis, MO) and $10 \%$ newborn calf serum (Life Technologies) (growth medium), at $37^{\circ} \mathrm{C}$ in an atmosphere of $5 \% \mathrm{CO}_{2}$ in air. The cells were passaged by treatment with $0.25 \%$ trypsin (Life Technologies).

\section{Cell viability assay}

For the analysis of viability, the cells were counted and seeded in 96-well plates in growth medium at concentration of $1 \times 10^{5}$ cells/well. After overnight incubation, the medium was removed and the cells were washed with phosphate-buffered saline (PBS). Four main cell groups were created: A control group (CG), a group treated with ZOL (ZOL monohydrate; SigmaAldrich), a group treated with $\mathrm{ZOL}$ and $\mathrm{GGOH}(\mathrm{GGOH}$; Sigma-Aldrich), and a group treated with $\mathrm{GGOH}$ only. ZOL was prepared by dissolving it in sterile, distilled, de-ionized water to obtain a stock solution of $6.9 \mathrm{mM}$, and diluted in serum-free DMEM containing $100 \mu \mathrm{g} / \mathrm{ml}$ gentamicin (DMEM-gent) for final concentrations of 5 , 25 , or $50 \mu \mathrm{M}$. These concentrations are equivalent to the concentrations of ZOL that the jawbone is exposed to in patients receiving the antiresorptive drug for 6-month, 2-year, and 4-year treatment, as previously calculated [2].

Another group received $\mathrm{ZOL}$ and $\mathrm{GGOH}$. A stock solution of $\mathrm{GGOH}$ at a concentration of $172 \mathrm{mM}$ was prepared by dissolving in $100 \%$ ethanol $(\mathrm{EtOH})$. $\mathrm{GGOH}$ was added to some cultures treated with $\mathrm{ZOL}$ for a final concentration of $50 \mu \mathrm{M}$ so that the final concentration of EtOH was 1\%. This concentration of EtoH is not toxic to GN23 or S-G cells [31].

In the next group, GGOH was added to the cells alone, at concentration of $50 \mu \mathrm{M}$, to test the possible negative or positive effects on the cells.

The CG of cells received DMEM-gent containing 1\% EtOH.

The MTT assay was performed after 3 days of incubation. The MTT test is used to evaluate the cell viability through cleaving of the yellow tetrazolium salt MTT into a purple formazan dye due to the metabolic activity of the cells. The purple formazan crystals are solubilized, resulting in a color change that is quantified with optic density determination. In the present study, the Cell Proliferation Kit I (MTT) (Sigma-Aldrich) was used. After a 3-day incubation of the cells with the respective chemicals, $10 \mu \mathrm{L}$ of the MTT labeling agent were added, followed by $4-\mathrm{h}$ incubation at $37^{\circ} \mathrm{C}$. Finally, the cells were exposed to $100 \mu \mathrm{L}$ of the MTT solvent 
overnight, under the same conditions. After the last cycle of incubation, the optic density of the solutions was read at $570 \mathrm{~nm}$ using a plate spectrophotometer (SPECTROstarNano; BMG Labtech GmbH, Offenburg, Germany).

\section{Cell morphology}

To test for the effects of $\mathrm{ZOL} \pm \mathrm{GGOH}$ on cell morphology, the cells were seeded at $1 \times 10^{5}$ per well of 6-well plates, in growth medium. After overnight incubation, the medium was removed and cells were washed with PBS, as described above. The cells then received DMEM-gent containing $50 \mu \mathrm{M} Z \mathrm{ZL} \pm 50 \mu \mathrm{M}$ $\mathrm{GGOH}$. Control cells received DMEM-gent containing $1 \% \mathrm{EtOH}$. After 3-day incubation, the cells were observed for morphological changes with an optical microscope (AxioScope A1, Germany) at different magnifications, connected with camera and imaging software (Axiocam MRC5). The cell morphology was described in terms of consistency of the cell form, cell membrane and detached cellular debris and compared to the findings from the cell viability test.

\section{Statistical analysis}

Data from the viability experiment were expressed as percentage of the CG. One-way analysis of variance and Tukey post-hoc comparisons were performed in the IBM SPSS Statistics 20 (SPSS Inc., Chicago, IL, USA) software for statistical analysis. The significance of $p$-value was set at 0.05 .

\section{Results}

\section{Cell viability}

Data are provided in Tables 1 and 2 and Figure $1 a$ and $b$. ZOL significantly decreased the viability of both the epithelial cells and gingival fibroblasts at all concentrations $(p<0.05)$, except for fibroblasts at the concentration of $5 \mu \mathrm{M}(p=0.44)$. The viability of the cells decreased gradually with the increasing concentration of ZOL. The epithelial cells were more susceptible to the effects of ZOL, compared to the gingival fibroblasts, especially at $50 \mu \mathrm{M} Z \mathrm{ZO}$ ( $p<0.05)$. The strongest significant difference among SG cells was observed between the CG and the group treated with $\mathrm{ZOL}$ at the highest concentration of the ZOL $(p<0.001)$.

GGOH did not affect the viability of the cells when added alone. Treatment with $\mathrm{GGOH}$ had positive effects on the viability of the cells treated with ZOL at all concentrations. However, statistically significant differences between the groups treated only with ZOL and those treated with $\mathrm{GGOH}$ were found only in the

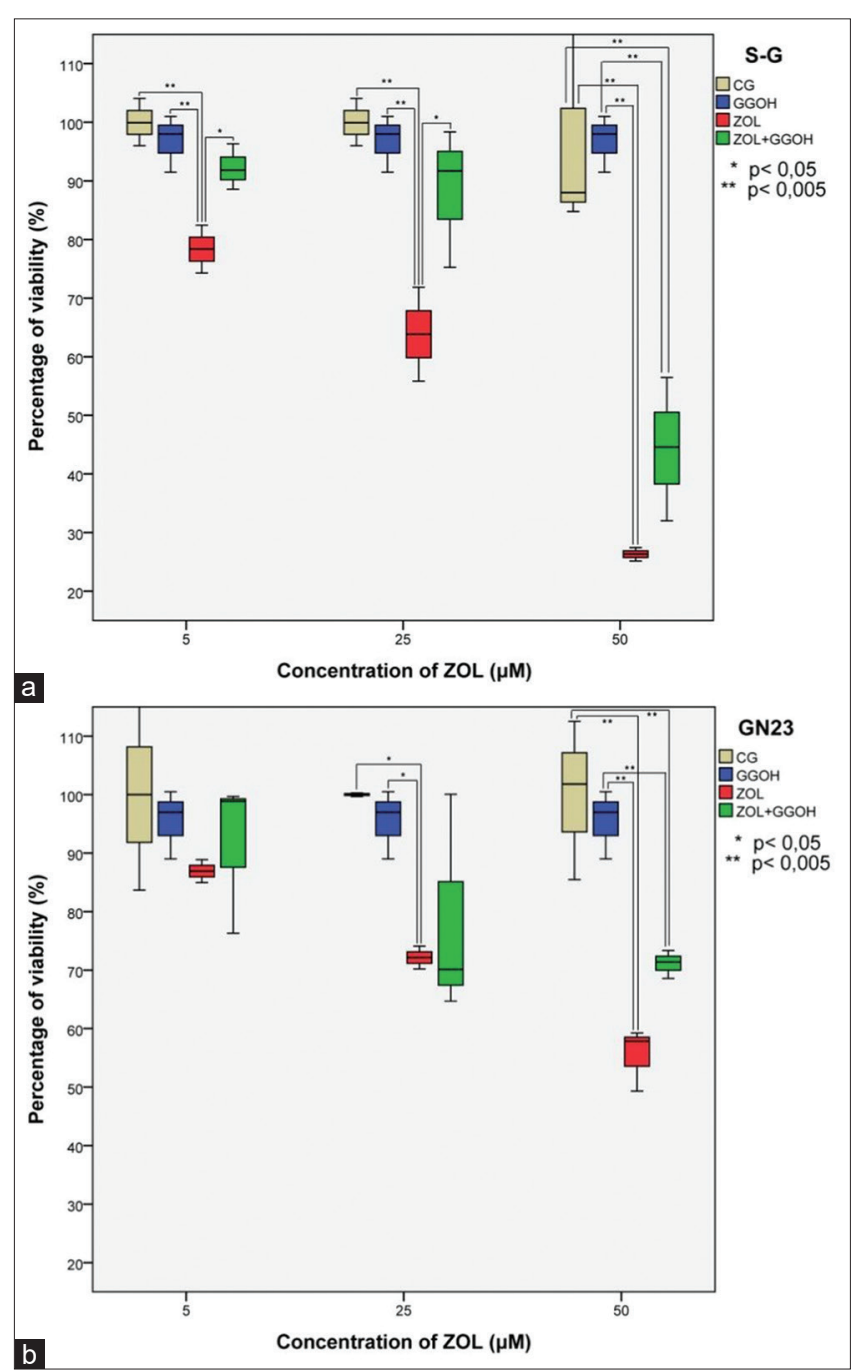

Figure 1: Effects of zoledronic acid (ZOL) and geranylgeraniol $(\mathrm{GGOH})$ on cell viability. (a) Gingival epithelial cells; (b) gingival fibroblasts. In both cell lines, there was a concentration-dependent inhibition of viability caused by ZOL. The fibroblasts were less susceptible to toxic effects of ZOL than epithelial cells. GGOH did not affected the cells when added alone, but improved the cell viability in both cell lines treated with ZOL. The significant differences between groups are marked with asterisks. The horizontal line in the bars represents the median value

epithelial cells at concentrations of ZOL of 5 and $25 \mu \mathrm{M}$ $(p<0.05)$. GGOH improved the viability of the treated cells with 5 and $25 \mu \mathrm{M}$ ZOL to the extent that there were no statistically significant differences between these groups and the CGs of both cell lines. However, the results show that there were also no statistical differences between the $\mathrm{ZOL}$ and $\mathrm{ZOL}+\mathrm{GGOH}$ groups in both cell lines at $50 \mu \mathrm{M} Z \mathrm{ZOL}$. The differences between the CG and the group treated with $\mathrm{GGOH}$ were very strong. The level of improvement of the cell viability between the two cell lines after the treatment with $\mathrm{GGOH}$ was similar at all concentrations of ZOL $(p>0.05)$.

\section{Cell morphology}

Both the epithelial cells and fibroblasts suffered significant impairments in the structure and morphology 
Table 1: Significance of differences between the groups in both cell lines, at different concentrations of ZOL

\begin{tabular}{|c|c|c|c|c|c|c|}
\hline \multirow[t]{3}{*}{ Group of cells } & \multicolumn{3}{|c|}{ S-G cells } & \multicolumn{3}{|c|}{ GN23 cells } \\
\hline & \multicolumn{6}{|c|}{ Concentration of ZOL } \\
\hline & $5 \mu \mathrm{M}$ & $25 \mu \mathrm{M}$ & $50 \mu \mathrm{M}$ & $5 \mu \mathrm{M}$ & $25 \mu \mathrm{M}$ & $50 \mu \mathrm{M}$ \\
\hline $\mathrm{CG} / \mathrm{GGOH}$ & $p=0.435$ & $p=0.435$ & $p=0.977$ & $p=0.690$ & $p=0.257$ & $p=0.632$ \\
\hline CG/ZOL & $p=0.001^{*}$ & $p=0.005^{*}$ & $p=0.001^{*}$ & $p=0.439$ & $p=0.049^{*}$ & $p=0.002^{*}$ \\
\hline $\mathrm{ZOL} / \mathrm{ZOL}+\mathrm{GGOH}$ & $p=0.013^{*}$ & $p=0.030^{*}$ & $p=0.252$ & $p=0.887$ & $p=0.782$ & $p=0.143$ \\
\hline $\mathrm{CG} / \mathrm{ZOL}+\mathrm{GGOH}$ & $p=0.120$ & $p=0.299$ & $p=0.005^{*}$ & $p=0.693$ & $p=0.115$ & $p=0.015^{*}$ \\
\hline
\end{tabular}

*Significant at $p$ < 0.05. S-G: Gingival epithelial cells; GN23: Gingival fibroblasts; ZOL: Zoledronic acid; CG: Control group; GGOH: Geranylgeraniol.

Table 2: Comparison of decrease of cell viability between the gingival epithelial cells and human gingival fibroblasts following the interference with ZOL and the effects after the treatment with GGOH

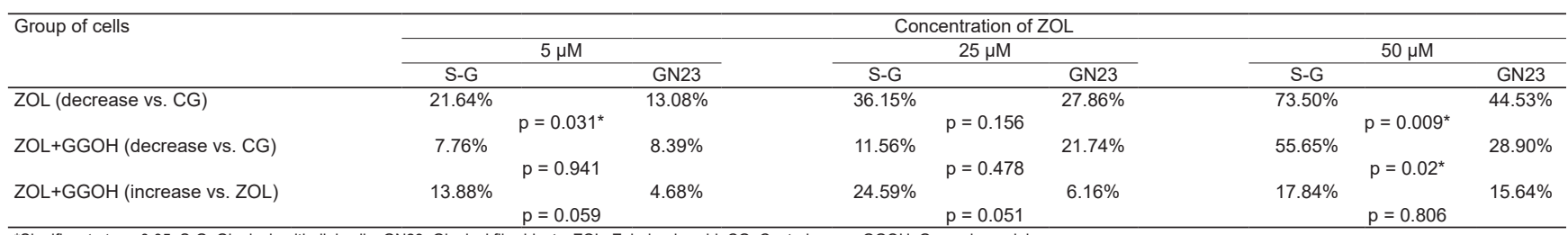

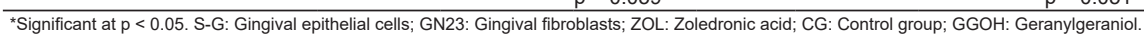
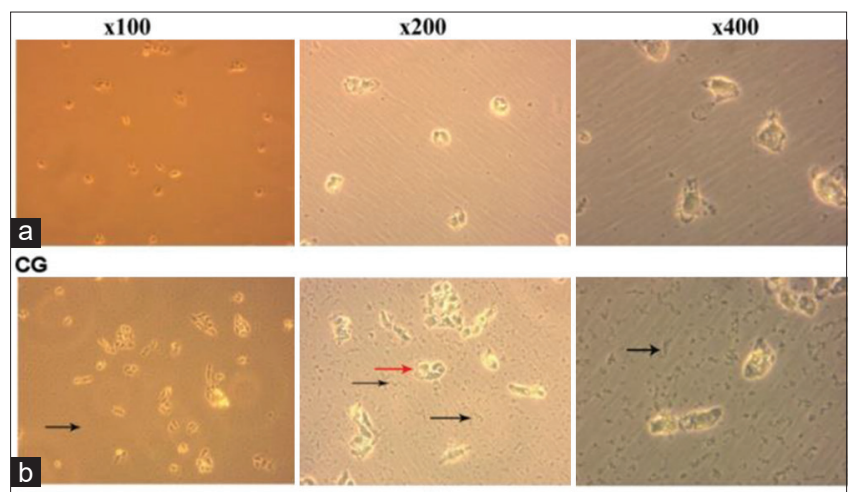

ZOL
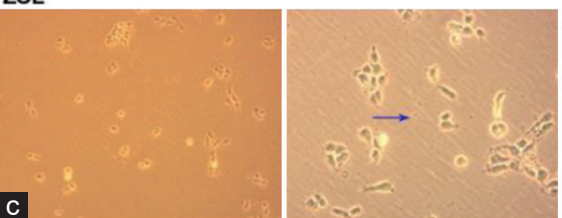

$\mathrm{ZOL}+\mathrm{GGOH}$

Figure 2: Light microscopic analysis of human gingival epithelial cells. (a) Control group; (b) group treated with $50 \mu \mathrm{M}$ zoledronic acid (ZOL); (c) group treated with $50 \mu \mathrm{M} Z \mathrm{ZOL}$ and $50 \mu \mathrm{M}$ geranylgeraniol (GGOH). ZOL significantly impaired the structure of the cells. Debris from dead and dying cells is visible (black arrow) and the cell membrane is damaged (red arrow). The addition of GGOH improved the cell structure and morphology. Less cellular debris is visible (blue arrow) and the shape of the cell membrane is improved (green arrow) (Light microscope, magnifications of $\times 100, \times 200$, and $\times 400$ )

after treatment with ZOL (Figures 2 and 3 ). Cellular debris from dead and dying cells were present throughout the cultures (Figures $2 \mathrm{~b}$ and $3 \mathrm{~b}$, black arrows). The cell membrane appeared to be discontinuous, which was particularly visible on the gingival fibroblasts (Figure 3b, red arrows). The changes in the structure and morphology of the cells are consistent with their decreased viability after exposure to ZOL. GGOH, on the other hand, improved the cytomorphology of both types of cells. Less cellular debris was noted (Figures $2 \mathrm{c}$ and $3 \mathrm{c}$, blue arrows), and the shape of the cells was improved (Figures 2c and 3c, green arrows).

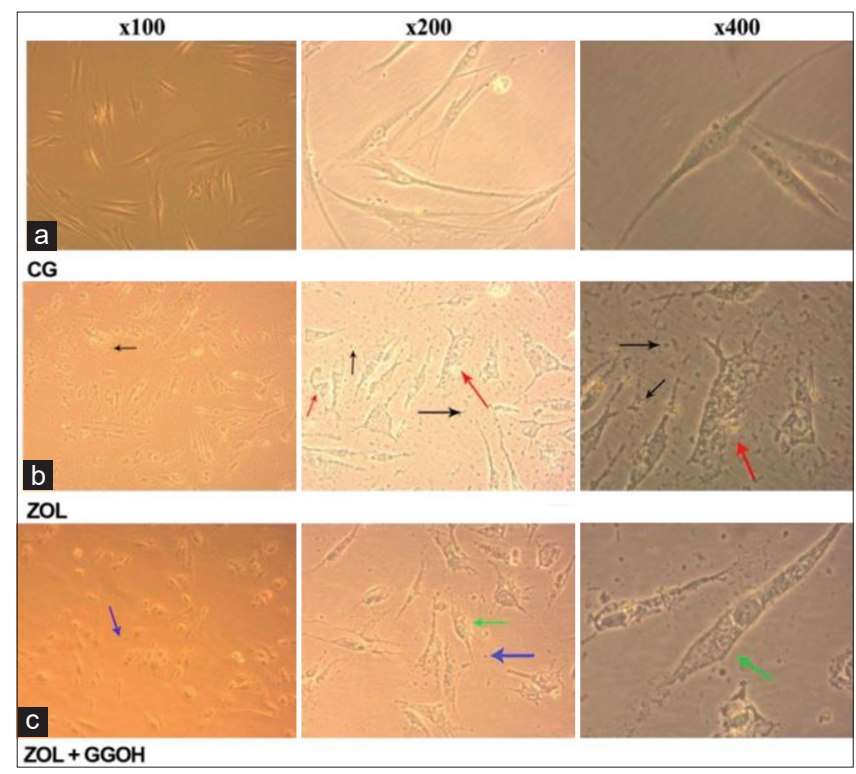

Figure 3: Light microscopic analysis of human gingival fibroblasts. (a) Control group; (b) group treated with $50 \mu \mathrm{M}$ zoledronic acid (ZOL); (c) group treated with $50 \mu \mathrm{M} Z \mathrm{ZL}$ and $50 \mu \mathrm{M}$ geranylgeraniol (GGOH). This cell line suffered significant structural impairment after the addition of ZOL. Cellular debris was visible throughout the plate (black arrow) and the cell membranes' shape was particularly affected (red arrow). Addition of GGOH improved the cell membrane shape (green arrow) and decreased the debris from damaged cells (blue arrow)

\section{Discussion}

The present study is one of the few that has investigated the possible positive effects of $\mathrm{GGOH}$ in the development of preventive and treatment strategies for MRONJ. It was designed to investigate how successfully this isoprenoid could interfere with the toxic action of BPs on human gingival epithelial cells and gingival fibroblasts. The findings indicate that the treatment of the cells with $\mathrm{GGOH}$ improved their viability and morphology after the impairment induced with ZOL. 
This study employed $\mathrm{ZOL}$, as a representative of nitrogen-containing BPs. These BPs enter cells and affect the metabolism of mevalonic acid or so-called mevalonate pathway [17]. The effect of the interference of BPs with this cellular activity is the lack of prenylation of proteins, and because the proteins are not supplemented with hydrophobic molecules, the small GTPases, such Ras, Rho, Rac, and Cdc42, are not activated [18], [19]. The absence of these signaling molecules is incompatible with normal cell function. The cells lose their ability to proliferate, migrate and regulate their morphology. ZOL is one of the most potent BPs and still one of the most widely used antiresorptive medications for treatment of malignancies and other metabolic diseases of the bones.

In the present study, ZOL decreased the viability and metabolic activity of the cells in a concentrationdependent manner. The previous studies have shown similar results. For example, Basso et al. [10] found that viability was reduced by ZOL by as much as $67 \%$ in human epithelial cells and $40 \%$ in gingival fibroblasts after a period of $48 \mathrm{~h}$. The greater susceptibility of the epithelial cells to the effects of high concentration of ZOL was consistent with the results of the present study. The percentage of proliferation of human gingival fibroblasts in the study of Scheper et al. [4] decreased by $30 \%$ and the viability decreased by $51 \%$ of the control after $24-h$ treatment with $3 \mu \mathrm{M}$ ZOL. The human keratinocytes were even more susceptible to the effects of $3 \mu \mathrm{M} Z O L$. The viability of gingival fibroblasts after 24-h and 48-h treatment with ZOL in the study of Walter et al. [5] was $80 \%$ and $40 \%$ of control, respectively. Similarly, another study also showed a significant decrease in the viability of human gingival fibroblasts after treatment with ZOL at concentrations of 5 and $50 \mu \mathrm{M}$. [6] Açil et al. noted a concentration-dependent decrease in viability of human oral fibroblasts treated with $\mathrm{ZOL}$ at concentrations from 1 to $100 \mu \mathrm{M}$ in one study [9] and lower concentrations in another recent study [12]. Ravosa et al. [7] found impaired transcription of type I collagen by human oral fibroblasts after a 48-h treatment with $10 \mu \mathrm{M} \mathrm{ZOL,}$ which is vital for granulation tissue and re-epithelization processes. Furthermore, it was shown in other studies that BPs affect cell migration, apoptosis rate, caspase 3 and 9 production and several aspects of osteoclastogenesis [3], [4], [8], [12], [22].

The first use of $\mathrm{GGOH}$ in experimental studies revealed that it prevents the activation of caspases and inhibits the osteoclastic resorption induced by nitrogencontaining BPs. In the present study, GGOH did not have negative or positive effects on the cells when added alone. This fact makes the CG relevant and allows the comparison to the other examined groups. The effects of GGOH against the toxicity induced by the potent BPs have been previously described on different cell lines in only few studies. The results of the present study indicate that GGOH positively influences the viability of gingival epithelial cells and gingival fibroblasts previously treated with ZOL. In general, the greater the damage, the higher level of reversal of toxicity was demonstrated. This suggests that $\mathrm{GGOH}$ enters the cells and mediates the prenylation of the small GTPases. However, a complete reversal of the toxicity was not noted in any of the cell groups, possibly due to the simultaneous negative effects of ZOL on the cellular enzymes responsible for the cell viability. Cozin et al. [6] used the same concentration of $\mathrm{GGOH}$ as the present study and found that it restored gingival fibroblast proliferation up to $75 \%$ of control after 168-h treatment with $8 \mu \mathrm{M} \mathrm{ZOL}$, and greater reversal of the negative effects of $Z O L$ on cell viability was demonstrated at higher concentrations. A complete rescue of the cells was found in the groups treated with $30 \mu \mathrm{M}$ of ZOL and $50 \mu \mathrm{M}$ GGOH. The studies of Ziebart et al. [20] and Pabst et al. [23] demonstrated significant improvement of fibroblasts and oral keratinocyte viability after treatment with 5 and $50 \mu \mathrm{M} \mathrm{ZOL}$ and $10 \mu \mathrm{M} \mathrm{GGOH}$.

The morphological analysis after the treatment with ZOL in this study showed significant impairment in both cell lines. Scheper et al. [4] and Basso et al. [10] had similar results in their studies, although they used different concentrations of ZOL. The partial improvement of cell viability after addition of $\mathrm{GGOH}$ in the present study was reflected in the changes in the morphological characteristics. These findings are consistent with the results of Cozin et al. [6] who found that $\mathrm{GGOH}$ almost completely restored the cytoskeletal structure and decreased the number focal adhesions in oral fibroblasts. Similar results were found in the study of Ziebart et al. [20]

In this study, the effects of $\mathrm{GGOH}$ were evaluated on cells treated with $\mathrm{ZOL}$ at concentrations that represent 6-month, 2-year, and 4-year duration of treatment in patients [2]. The previous studies implemented different concentrations either of ZOL or $\mathrm{GGOH}$ and different treatment duration. Therefore, this study offers an insight into this quite complex area for a possible solution.

Gingival epithelial cells and gingival fibroblasts play important roles in wound healing after invasive oral procedures [1]. These procedures remain the major risk factor for development of MRONJ. Previously conducted animal studies demonstrated that tooth extraction initiates bone necrosis in rats treated with ZOL [13], [14]. However, some degree of necrosis was also observed even when there was only soft-tissue trauma [15]. It is thought that after invasive dental procedures and soft-tissue trauma, a local decrease of $\mathrm{pH}$ occurs, usually accompanied by the entrance of the local bacteria and other pathogens into the tissues. Under conditions of decreased $\mathrm{pH}$ and osteoclastmediated bone resorption, the soluble BPs, such as $\mathrm{ZOL}$, are released into the local tissue. Although it is hard to determine the exact amount of released $\mathrm{ZOL}$ from the bone, it is assumed that epithelial cells and 
fibroblasts are readily exposed and susceptible to the toxic effects of the released BP. This explains the findings of decreased wound healing and necrotic bone exposure. In the present study, GGOH partially reversed the toxic effects of ZOL on cells in vitro.

The topical use of GGOHin an animal model has been investigated only in one study. Koneski et al. [25] found that local administration of $\mathrm{GGOH}$ significantly improved the clinical wound healing and decreased the occurrence and severity of bone necrosis. In another study, Nagaoka et al. [26] applied GGOH systemically and found increased bone deposition near the bone defect, which illustrates the effects of this isoprenoid on bone. It is possible that the systemic administration of $\mathrm{GGOH}$ would interfere with the beneficial therapeutic effects of ZOL, since they target the same enzymatic processes.

Recently, more attention has been paid to soft tissue toxicity and the role of infection and inflammation in the development of MRONJ.

For a complete picture, further studies should employ all kinds of cells that are involved in postextraction healing process, not only soft-tissue cells. This might be one of the limitations of the present study. Moreover, there are a number of laboratory tests that could be implemented, besides cell viability test, to analyze the cell behavior in the conditions of interest.

\section{Conclusion}

GGOH significantly reverses the toxicity and improves the viability of gingival epithelial cells previously treated with ZOL at concentrations which correspond with the clinical course of treatment, while the effect on the gingival fibroblasts is only slight. The cell morphology is positively affected by $\mathrm{GGOH}$. The possible implementation of $\mathrm{GGOH}$ should be further examined for treatment of MRONJ, and additional in vitro and in vivo studies are necessary. Different concentrations, treatment duration, method and route of administration, and possible side effects should be analyzed. Moreover, the effects of $\mathrm{GGOH}$ when combined with the present preventive measures may reveal new perspectives of treatment of MRONJ.

\section{References}

1. Ruggiero SL, Dodson TB, Fantasia J, Goodday R, Aghaloo T, Mehrotra B. American association of oral and maxillofacial surgeons position paper on medication-related osteonecrosis of the jaw-2014 update. J Oral Maxillofac Surg. 2014;72(10):193856. https://doi.org/10.1016/j.joms.2014.04.031

\section{PMid:25234529}

2. Otto S, Pautke C, Opelz C, Westphal I, Drosse I, Schwager J, et al. Osteonecrosis of the jaw: Effect of bisphosphonate type, local concentration, and acidic milieu on the pathomechanism. J Oral Maxillofac Surg. 2010;68(11):2837-45. https://doi. org/10.1016/j.joms.2010.07.017

PMid:20971371

3. Landesberg R, Cozin M, Cremers S, Woo V, Kousteni S, Sinha S, et al. Inhibition of oral mucosal cell wound healing by bisphosphonates. J Oral Maxillofac Surg. 2008;66:839-47. https://doi.org/10.1016/j.joms.2008.01.026 PMid:18423269

4. Scheper MA, Badros A, Chaisuparat R, Cullen KJ, Meiller TF. Effect of zoledronic acid on oral fibroblasts and epithelial cells: A potential mechanism of bisphosphonate-associated osteonecrosis. Br J Haematol. 2009;144(5):667-76. https://doi. org/10.1111/j.1365-2141.2008.07504.x PMid: 19036117

5. Walter C, Klein MO, Pabst A, Al-Nawas B, Duschner H, Ziebart T. Influence of bisphosphonates on endothelial cells, fibroblasts, and osteogenic cells. Clin Oral Investig. 2010;14(1):35-41. https://doi.org/10.1007/s00784-009-0266-4

PMid:19294435

6. Cozin M, Pinker BM, Solemani K, Zuniga JM, Dadaian SC, Cremers $S$, et al. Novel therapy to reverse the cellular effects of bisphosphonates on primary human oral fibroblasts. J Oral Maxillofac Surg. 2011;69(10):2564-78. https://doi.org/10.1016/j. joms.2011.03.005

PMid:21807448

7. Ravosa MJ, Ning J, Liu Y, Stack MS. Bisphosphonate effects on the behaviour of oral epithelial cells and oral fibroblasts. Arch Oral Biol. 2011;56(5):491-8. https://doi.org/10.1016/j. archoralbio.2010.11.003

PMid:21146154

8. Tipton DA, Seshul BA, Dabbous MK. Effect of bisphosphonates on human gingival fibroblast production of mediators of osteoclastogenesis: RANKL, osteoprotegerin and interleukin-6. J Periodontal Res. 2011;46(1):39-47. https://doi. org/10.1111/j.1600-0765.2010.01306.x

PMid:20701670

9. Açil Y, Möller B, Niehoff P, Rachko K, Gassling V, Wiltfang J, et al The cytotoxic effects of three different bisphosphonates in vitro on human gingival fibroblasts, osteoblasts and osteogenic sarcoma cells. J Craniomaxillofac Surg. 2012;40(8):e229-35. https://doi.org/10.1016/j.jcms.2011.10.024

PMid:22082730

10. Basso FG, Pansani TN, de Oliveira CF, Turrioni AP, Soares DG, Hebling $J$, et al. Cytotoxic effects of zoledronic acid on human epithelial cells and gingival fibroblasts. Braz Dent J. 2013;24(6):551-8. https://doi. org/10.1590/0103-6440201302229

PMid:24474348

11. Walter C, Pabst A, Ziebart T, Klein MO, Al-Nawas B. BisphosphonatesaffectmigrationabilityandcellviabilityofHUVEC, fibroblasts and osteoblasts in vitro. Oral Dis. 2017;17(2):194-9. https://doi.org/10.1111/j.1601-0825.2010.01720.x PMid:20796232

12. Açil $Y$, Arndt $M L$, Gülses $A$, Wieker $H$, Naujokat $H$, Ayna $M$, et al. Cytotoxic and inflammatory effects of alendronate and zolendronate on human osteoblasts, gingival fibroblasts and osteosarcoma cells. J Craniomaxillofac Surg. 2018;46(4):53846. https://doi.org/10.1016/j.jcms.2017.12.015 PMid:29454604

13. Otto S, Pautke C, Jurado OM, Nehrbass D, Stoddart MJ, Ehrenfeld M, et al. Further development of the MRONJ minipig 
large animal model. J Craniomaxillofac Surg. 2017;45(9):150314. https://doi.org/10.1016/j.jcms.2017.07.002 PMid:28803745

14. Soundia A, Hadaya D, Esfandi N, Gkouveris I, Christensen R, Dry SM, et al. Zoledronate impairs socket healing after extraction of teeth with experimental periodontitis. J Dent Res. 2018;97(3):312-20. https://doi.org/10.1177/0022034517732770 PMid:28954199

15. Zandi M, Dehghan A, Janbaz P, Malekzadeh H, Amini P. The starting point for bisphosphonate-related osteonecrosis of the jaw: Alveolar bone or oral mucosa? A randomized, controlled experimental study. J Craniomaxillofac Surg. 2017;45(1):15761. https://doi.org/10.1016/j.jcms.2016.10.015 PMid:27919595

16. Popovik-Monevska D, Muratovska I, Popovska M, Dvojakovska S, Koneski F. Osteoradionecrosis of the mandible: A case report. Balkan J Dent Med. 2015;20:54-8. https://doi. org/10.1515/bjdm-2016-0009

17. Luckman SP, Hughes DE, Coxon FP, Russell RG, Rogers MJ. Nitrogen-containing bisphosphonates inhibit the mevalonate pathway and prevent post-translational prenylation of GTP-binding proteins, including Ras. J Bone Miner Res. 1998;13(4):581-9. https://doi.org/10.1359/jbmr.1998.13.4.581 PMid:9556058

18. Li X, Liu L, Tupper JC, Bannerman DD, Winn RK, Sebti SM, et al. Inhibition of protein geranylgeranylation and RhoA/RhoA kinase pathway induces apoptosis in human endothelial cells. $J$ Biol Chem. 2002;277(18):15309-16. https://doi.org/10.1074/jbc. m201253200

PMid:11839765

19. Hagelauer N, Ziebart T, Pabst AM, Walter C. Bisphosphonates inhibit cell functions of HUVECs, fibroblasts and osteogenic cells via inhibition of protein geranylgeranylation. Clin Oral Investig. 2015;19:1079-91. https://doi.org/10.1007/s00784-014-1320-4 PMid:25261400

20. Ziebart T, Koch F, Klein MO, Guth J, Adler J, Pabst A, et al. Geranylgeraniol-a new potential therapeutic approach to bisphosphonate associated osteonecrosis of the jaw. Oral Oncol. 2011;47(3):195-201. https://doi.org/10.1016/j. oraloncology.2010.12.003

PMid:21247791

21. Zafar S, Coates DE, Cullinan MP, Drummond BK, Milne T, Seymour GJ. Zoledronic acid and geranylgeraniol regulate cellular behaviour and angiogenic gene expression in human gingival fibroblasts. J Oral Pathol Med. 2014;43(9):711-21. https://doi.org/10.1111/jop.12181

\section{PMid:24762323}

22. Zafar S, Coates DE, Cullinan MP, Drummond BK, Milne T, Seymour GJ. Effects of zoledronic acid and geranylgeraniol on the cellular behaviour and gene expression of primary human alveolar osteoblasts. Clin Oral Investig. 2016;20(8):2023-35. https://doi.org/10.1007/s00784-015-1706-y

\section{PMid:26795621}

23. Pabst $A M$, Krüger $M$, Ziebart $T$, Jacobs $C$, Sagheb $K$ Walter $\mathrm{C}$. The influence of geranylgeraniol on human oral keratinocytes after bisphosphonate treatment: An in vitro study. J Craniomaxillofac Surg. 2015;43(5):688-95. https://doi. org/10.1016/j.jcms.2015.03.014

\section{PMid:25913629}

24. Pabst AM, Krüger M, Sagheb K, Ziebart T, Jacobs C, Blatt S, et al. The influence of geranylgeraniol on microvessel sprouting after bisphosphonate substitution in an in vitro 3D-angiogenesis assay. Clin Oral Investig. 2017;21(3):771-8. https://doi. org/10.1007/s00784-016-1842-z

PMid:27170294

25. Koneski F, Popovic-Monevska D, Gjorgoski I, Krajoska J, Popovska M, Muratovska I, et al. In vivo effects of geranylgeranio on the development of bisphosphonate-related osteonecrosis of the jaws. J Craniomaxillofac Surg. 2018;46(2):230-6. https://doi. org/10.1016/j.jcms.2017.11.007

PMid:29233701

26. Nagaoka Y, Kajiya H, Ozeki S, Ikebe T, Okabe K. Mevalonates restore zoledronic acid-induced osteoclastogenesis inhibition. J Dent Res. 2015;94(4):594-601. https://doi. org/10.1177/0022034514564187

\section{PMid:25535203}

27. Tipton DA, Pabst MJ, Dabbous MK. Interleukin-1 beta-and tumor necrosis factor-alpha-independent monocyte stimulation of fibroblast collagenase activity. J Cell Biochem. 1990;44(4):25364. https://doi.org/10.1002/jcb.240440407 PMid:1965653

28. Smulow J, Glickman I. An epithelial-like cell line in continuous culture from normal adult human gingiva. Proc Soc Exp Biol Med. 1966;121(3):1294-6. https://doi. org/10.3181/00379727-121-31032

PMid:5937747

29. Sonnenschein C, Smulow J. Karyotypic analysis of an epithelial-like cell line derived from normal adult human gingiva. Exp Cell Res. 1966;43(3):633-8. https://doi. org/10.1016/0014-4827(66)90034-6

\section{PMid:5957752}

30. Kasten FH, Seileu K, Nefert RM. Quantitative evaluation of human gingival epithelial cell attachment to implant surfaces in vitro. Int J Periodontics Restorative Dent. 1990;10(1):68-79. PMid:2394556

31. Tipton DA, Lyle B, Babich H, Dabbous MK. In vitro cytotoxic and anti-inflammatory effects of myrrh oil on human gingival fibroblasts and epithelial cells. Toxicol In Vitro. 2003;17(3):30110. https://doi.org/10.1016/s0887-2333(03)00018-3 PMid:12781209 